\title{
Diagnosis and Management of Cavernous Hemangioma of the Tongue with Sclerosing Agents: A Case Report and Review of Literature
}

\author{
Deepak Gupta ${ }^{1 \star}$, Sanjeev Gupta ${ }^{2}$, Amit Mittal ${ }^{3}$, Preeti Garg ${ }^{1}$
}

\begin{abstract}
${ }^{1}$ Department of Oral Medicine and Radiology, M.M. College of Dental Sciences and Research, M.M. (Deemed to be University), Mullana, Ambala, Haryana, INDIA ${ }^{2}$ Professor and Head, Department of Dermatology. MMIMSR, M.M. (Deemed to be University), Mullana, Ambala, Haryana, INDIA

${ }^{3}$ Professor and Head, Department of Radiology and Imaging, M.M. (Deemed to be University), Mullana, Ambala, Haryana, INDIA *Corresponding Author: drdeepak_26@rediffmail.com
\end{abstract}

Citation: Gupta D, Gupta S, Mittal A, Garg P. Diagnosis and Management of Cavernous Hemangioma of the Tongue with Sclerosing Agents: A Case Report and Review of Literature. Electron J Gen Med. 2021;18(5):em307. https://doi.org/10.29333/ejgm/11016

\section{ARTICLE INFO}

Received: 2 Mar. 2021

Accepted: 25 Apr. 2021

\begin{abstract}
Vascular anomalies pose as one of the most difficult diagnostic and therapeutic enigma in the maxillofacial region. They comprise of two categories i.e hemangioma and vascular malformation. Hemangiomas are tumors of blood vessels which present after birth, undergo a proliferative phase with rapid growth and then undergo a stationary period followed by a period of involution. In contrast vascular malformations are always present at birth and enlarge in proportion to growth of an individual, do not involute and present throughout patient's life. Haemangioma is the most common benign tumour of vascular origin of the maxillofacial region. Despite its benign origin and behaviour, it is always of clinical importance to the dental professionals and requires appropriate management as it may lead to an early or continuous loss of function or lifetime esthetic impairment. Hemangioma can be subdivided into superficial type also known as capillary hemangioma which presents as bright red macular masses; and deep hemangioma known as cavernous hemangioma which presents as soft, nonfluctuant, poorly defined, dome like, bluish and occasionally bosselated nodule. Herein, we present a case of a 65 year old female presenting with deep or cavernous hemangioma on the lateral border of the tongue treated with $1 \%$ sodium tetradecyl sulphate with successful remission of the lesion. Usually such patients require surgical removal of the lesion. But in consideration to the massive surgical procedure, this therapeutic approach may reduce the chances of the surgical requirement.
\end{abstract}

Keywords: Cavernous Hemangioma, tongue, $3 \%$ sodium tetradecyl sulphate

\section{INTRODUCTION}

Hemangiomas are the tumors of vascular origin comprising approximately $7 \%$ of all benign tumors of maxillofacial region [1]. They are characterized by an abnormal proliferation of blood vessels. These are mesenchymal in origin and are considered as benign congenital hamartomas [2]. It has been suggested that they arise from malformed tissue that has been subjected to repeated trauma or are the result of hormonal factors [3]. Approximately50\% occur in the first decade, with $94 \%$ occurring before the age of 30 years [4]. Adult hemangiomas are distinct from pediatric hemangiomas, which proliferate during infancy and then involute slowly for several years, followed by eventual regression [5]. The majority of haemangioma involve the head and neck $[6,7]$. However, they are rare in the oral cavity $[8,9]$, but may occur on tongue, lips, buccal mucosa, gingiva, palatal mucosa, salivary glands, alveolar ridge, and jaw bones [7]. Females appear to have a slightly higher incidence than males [6]. Prevalence of hemangioma in the oral cavity is $8 / 1000$ in males and 4/1000 in females [10]. The oral cavity, head and neck regions possess complex, rich and intricate blood vessels which might be a predisposing factor for a variety of vascular lesions. Clinically, haemangioma appears as a soft mass, smooth or lobulated, and sessile or pedunculated and may vary in size from a few $\mathrm{mms}$ to several cms. They are usually deep red or bluish in appearance and may blanch on the application of pressure and if large in size, might interfere with mastication [7].

Hemangiomas are classified as capillary and cavernous on the basis of the vascularization system [2]. Capillary type is characterized predominantly by capillary structures with proliferative activity, invasion to surrounding tissue and short clinical history [11-12]. Cavernous type is characterized by large vessels with occasional mitotic activity and longer clinical history [11,12]. The incidence of cavernous hemangioma of the head and neck is about $5 \%$ of the vascular malformations diagnosed by angiography and histology [10]. Commonly seen in 3rd to 5th decade of life, also seen in children and elderly patients [10]. Seventy percent of cavernous hemangiomas resolve on their own by the time of adolescence and $50 \%$ have an association with the skin hemangioma [13].

Clinically, cavernous hemangiomas occur twice as often in females as in males [14], and are larger, less well circumscribed and do not show tendency to regress. 

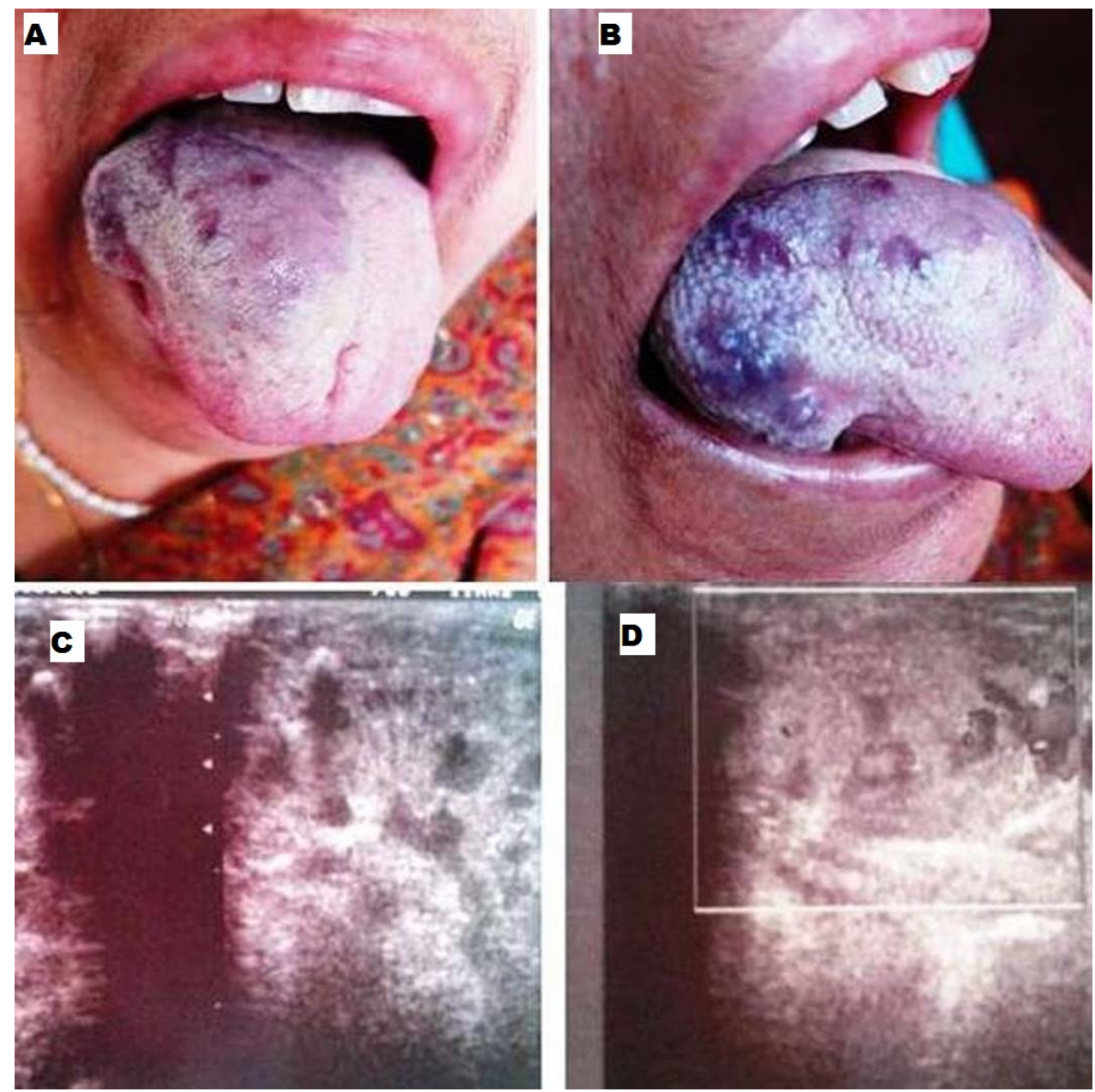

Figure 1. A and B reveals Intraoral solitary purple colored nodular swelling evident over right lateral posterior region of tongue. C and $D$ reveals Pretreatment Ultrasonography pictures of the patient revealing presence of multiple dilated cystic channels showing low velocity venous flow on color Doppler with phleboliths seen in dilated channels suggestive of hemangioma of tongue.

For the diagnosis of cavernous hemangiomas, bidigital palpation of the region and detection of disappearance of the blood due to finger pressure and after removal of finger pressure observation of revascularization are important signs [2].

Among the different sites of head and neck hemangiomas, the tongue requires special consideration because of its susceptibility to minor trauma and consequent bleeding and ulceration. It may also lead to swallowing difficulties and breathing problem. Although the major concern is cosmetic issues in most cases $[15,16]$.

Mostly hemangiomas regress in response to medical treatment or with conservative management $[6,17]$. Observation is the main treatment for hemangioma, but due to the intolerable symptoms it causes in cases involving tongue, patients seek more invasive types of treatment. The recommended treatment of hemangioma in special situations is administration of intralesional sclerosing agents or surgical removal can also be done [15].

We intend to highlight the diagnosis of a case of cavernous hemangioma involving tongue with special emphasis on treatment with the use of intralesional sclerosing agent with successful remission of the lesion.

\section{CASE PRESENTATION}

A 60 year-old female reported with a chief complaint of swelling on the right side of tongue since 40 years. Initially the swelling was of pea size which has increased gradually and reached the present size. It was not associated with pain but was interfering in mastication.

On examination a solitary purple colored nodular compressible swelling measuring approximately $4 \mathrm{~cm} \mathrm{x} 4 \mathrm{~cm}$ x $3 \mathrm{~cm}$ in dimensions was present over right lateral posterior region of tongue (Figure 1). It was non-tender on palpation. The diascopy test was positive resulting in blanching of the lesion when pressing with a microscope glass slide which pointed towards the vascular nature of the lesion.

\section{Investigation}

The patient was then subjected to ultrasonography (Figure 1) followed by magnetic resonance imaging (MRI) scan. Ultrasonography revealed presence of multiple dilated cystic channels showing low velocity venous flow on color Doppler with phleboliths seen in dilated channels. These findings were suggestive of hemangioma of tongue (Figure $\mathbf{1}$ ).

Magnetic resonance imaging revealed large well circumscribed lobulated mass lesion measuring $4.2 \mathrm{~cm} \times 3.6 \mathrm{~cm}$ seen in the antero superior part of the tongue appearing as iso intense on T1W and hyper intense on T2W with small hypo 


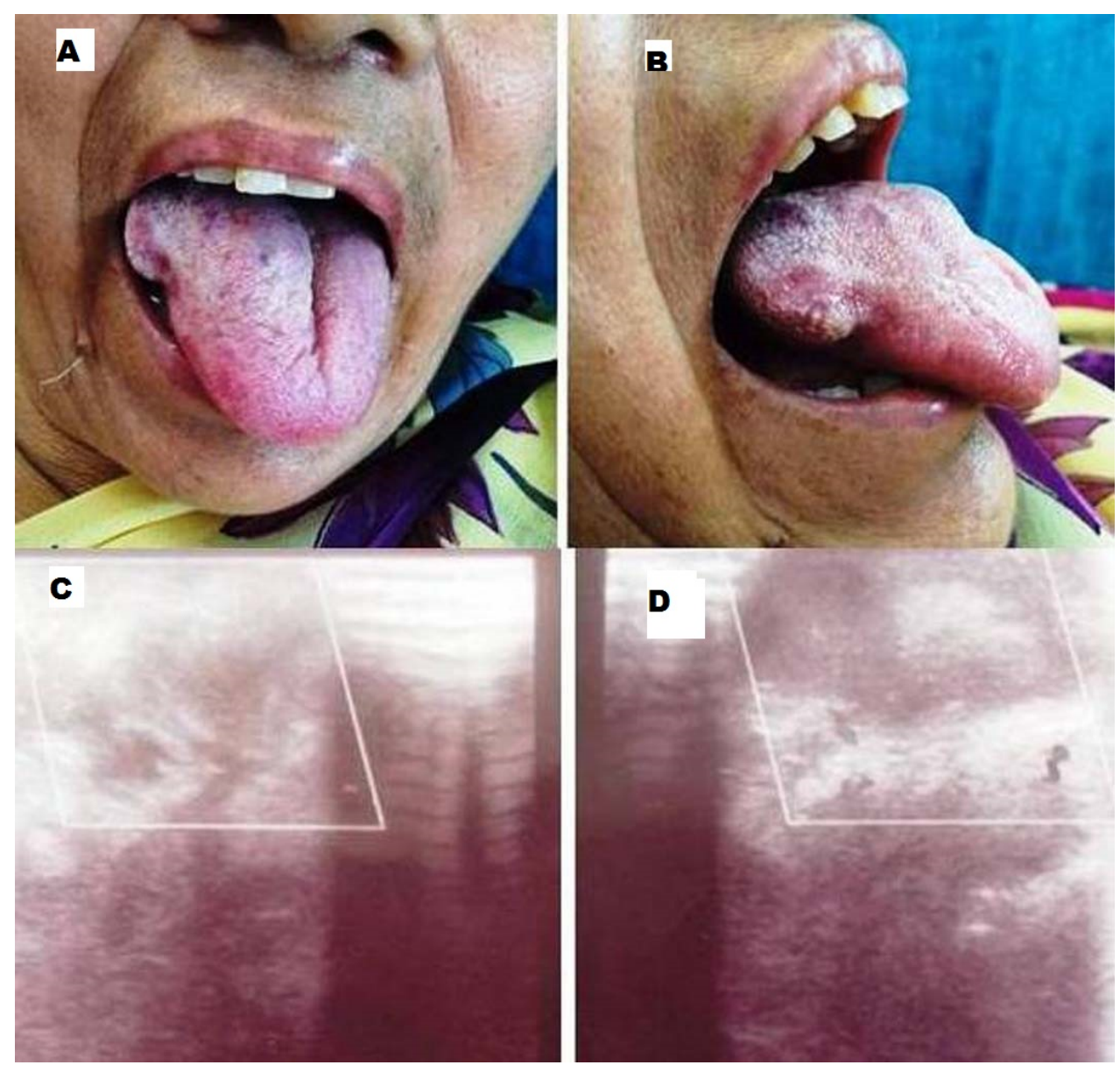

Figure 2. A and B reveals the patient's profile of the tongue with reduced size of the lesion after 15th day. C and D reveals Post treatment Ultrasound pictures of the tongue after two months of the injection therapy revealing heterogenous soft tissue mass in the tongue without any flow on color Doppler suggestive of Sclerosed tongue.

intense septations seen within it. Small phleboliths appearing hypo intense on TIW/T2W images were also seen within it. The mass lesion was involving the genioglossus, superior longitudinal and transverse muscles of the tongue. Laterally the mass was abutting the lingual surface of the mandibular alveolus on right side. These findings were suggestive of hemangioma.

\section{Treatment}

In consideration to the large size of the lesion and the anatomic location over the highly vascularized structure of the oral cavity, i.e., tongue, conservative treatment modality was performed by sclerotherapy with $1 \%$ sodium tetra decyl sulfate (STS). A test dose of $1 \%$ STS was given to check for the signs of hypersensitivity. $1 \%$ STS was prepared by diluting $2 \mathrm{ml}$ of $3 \%$ STS with $6 \mathrm{ml}$ of normal saline in two syringes each comprising of $1 \mathrm{ml} \mathrm{STS}$ and $3 \mathrm{ml}$ of normal saline. The area to be injected was cleansed and local infiltration (2\% lignocaine with 1:2,00,000 adrenaline) was administered at the base and periphery of the lesion. After that $1 \%$ STS was injected directly into the lesion through the mucosa at multiple sites. The decision of volume of the sclerosing agent to be injected was based upon the volume/size of lesion. Further care was taken to fill the lesion properly with the sclerosing agent until the lesion blanched. Total preparation of the sclerosing agent was $8 \mathrm{ml}(2 \mathrm{ml}$ of agent and $6 \mathrm{ml}$ of normal saline). Once the lesion was filled properly, the syringe was withdrawn and rest of the solution was discarded. We injected almost $5.5 \mathrm{ml}$ of the agent. After withdrawal of the needle, manual compression for 10-15 min was done over the lesion with sterile gauze. The patient was advised to take anti-inflammatory drugs, i.e., Divon-S twice a day for 3 days and patient was recalled after 15 days. After 4-5 injections of sclerosing agent patient reported with regression in size of the lesion. The patient was kept on follow up.

\section{Outcome and Follow up}

Patient presented with reduced size of the lesion after $15^{\text {th }}$ day (Figure 2). Ultrasound of the tongue was repeated after two months of the injection therapy. The report revealed heterogenous soft tissue mass in the tongue without any flow on color Doppler suggestive of Sclerosed tongue (Figure 2). The injections were repeated and follow up was taken for 3 to 4 subsequent visits (Figure 3 ). The patient showed significant reduction in the size of the lesion. Ultrasound was repeated again which revealed completely sclerosed tongue (Figure 3 ).

\section{DISCUSSION}

Hemangioma (Greek: Haima-blood; angeion- vessel, oma tumor) by definition can be defined as "a benign tumor of dilated blood vessels." It can present as port-wine stain, strawberry hemangioma, and Salmon patch. It is characterized by hyperplasia of blood vessels, usually veins and capillaries, in a focal area of submucosal connective tissue [18]. 


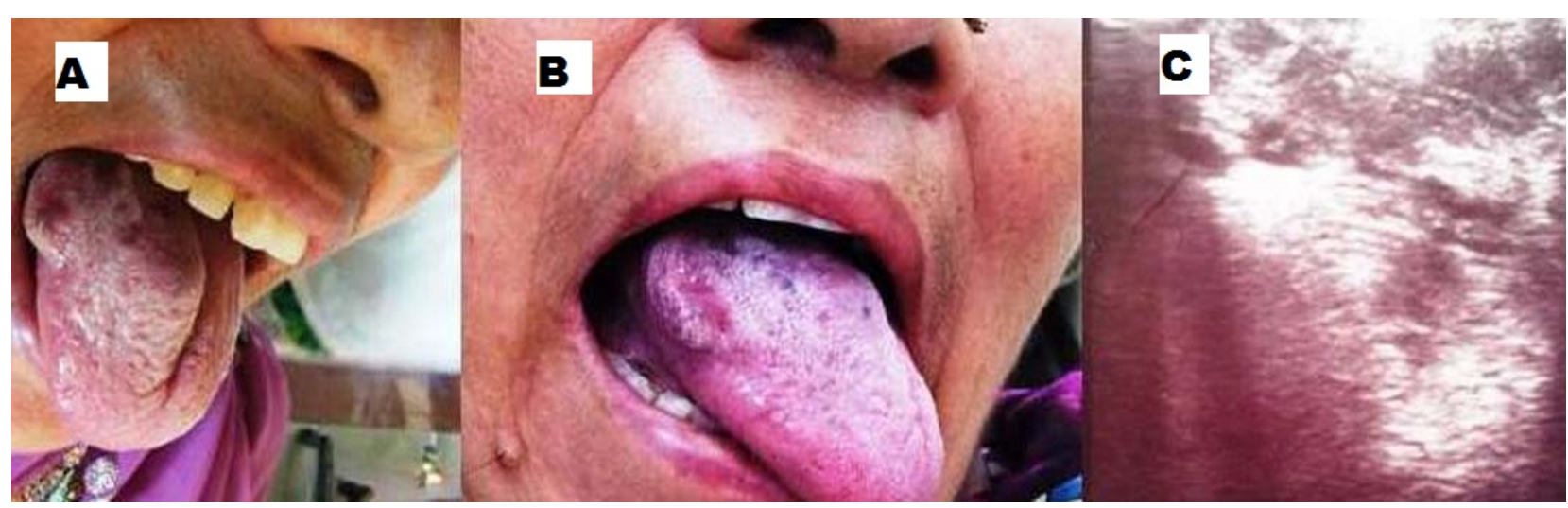

Figure 3. A and B reveals follow up of the patient after 5 months and 10 months respectively revealing reduction in the clinical size of the lesion. $C$ reveals Ultrasound repeated after one year revealing completely sclorsed tongue.

As already stated, hemangioma are a variety of vascular anomalies these can be mistaken for venous malformations which are most common vascular malformations as they appear similar clinically, it can result in potentially serious complications in management as these malformations are congenital and do not involute with time [18].

Hemangiomas have a different life cycle, being characterized by 3 stages: endothelial cell proliferation, rapid growth and spontaneous involution [19]. Hemangioma are vasoproliferative tumorsresulting from vasculogenesis rather than from angiogenesis. The hallmark of a growing hemangioma is endothelial cell proliferation. During the phase of rapid growth, hemangiomas over express cytokines and other molecules known to play a role in angiogenesis. These include FGF-2, VEGF-A, and matrix metalloproteinases. During the involution phase, mesenchymal stem cells differentiate into adipocytes, whereas capillary lumens undergo apoptosis, both of which lead to lesion resolution [18-22].

Anatomist and obstetrician William Hunter fist described vascular anomalies in the mid-18th century in the context of iatrogenic creation of arterio-venous fistulas by phlebotomists [18]. Over the next century, description of these and more complex vascular lesions was furthered by the work of Dupuytren, Virchow, and others but the lack of a cohesive system of classification led to confusion, hampering further understanding of these entities [18].

In 1982, Mulliken and Glowacki proposed a binary classification system for vascular anomalies based on pathologic features. This system, which was adopted by the International Society for the Study of Vascular Anomalies (ISSVA), has since been expanded and is now widely accepted. The importance of the ISSVA system is that it allows a systematic approach to vascular lesions that correlates predictably with clinical history, disease course, and treatment options, making it clinically useful.

The ISSVA classification system divides vascular anomalies into 2 biological categories: (1) Vaso-proliferative or vascular neoplasms and (2) Vascular malformations. The major distinction between the 2 categories is whether there is increased endothelial cell turnover, which is ultimately determined by the identification of mitoses seen on histopathology. Vasoproliferative neoplasms have increased endothelial cell turnover (i.e., they proliferate and undergo mitosis) because they are neoplasms. Vascular malformations do not have increased endothelial cell turnover [19].
The terms capillary and cavernous haemangioma are out of date and the lesions are more appropriately described according to the depth of the lesion as superficial, deep, and compound haemangioma [19-23]. Superficial haemangiomas originate from the papillary dermis and present as bright red macular or papular masses (previously called capillary or strawberry haemangioma). Deep hemangiomas originate from the reticular dermis or subcutaneous tissues and appear as bluish or relatively colourless masses (previously called cavernous haemangioma). They are typically soft, nonfluctuant, poorly defined, dome like, bluish and occasionally bosselated nodule that may vary in size from few $\mathrm{mm}$ to $\mathrm{cms}$ and readily blanch with compression as seen in this case. This gives them a characteristic "bag of worms" feel. It frequently occurs on the lips, buccal mucosa, palate and other sites in the oral cavity.

The medical history of the patient, timing of manifestation of the lesion, clinical examination for degree of swelling, local temperature, color of lesion and changes in dependent position are essential and sufficient to make a working or clinical diagnosis of a vascular lesion.

The primary goals of imaging vascular malformations or hemangiomas include characterizing the lesion and discovering the anatomic extent of disease. Knowing which tissues the vascular malformation involves and whether adjacent vital structures, such as neurovascular bundles, are involved by the lesion is important [14].

In this present case Ultrasonography (USG) and magnetic resonance imaging (MRI) were used as the diagnostic imaging modalities of choice. USG is used for initial screening because of its portability, lack of ionizing radiation, and no requirement of sedation in children. It is relatively simple, noninvasive, and yields good results for evaluating small, superficial and/or suspected, solid visceral lesions. Typically, USG is able to determine the basic type of lesion, direct initial management, and plan further imaging evaluation. For sonography to be a useful modality, it must include grayscale, color Doppler, and spectral Doppler tracings to evaluate vascularity and determine types of vessels present. In this present case Ultrasonography revealed multiple dilated cystic channels showing low velocity venous flow on color Doppler with phleboliths seen in dilated channels which is diagnostic for hemangioma [14].

MRI is helpful to further characterize sonographic findings and determine the extent of larger lesions for planning medical, interventional, and/or surgical therapy. Most 
information needed to examine the lesion is available from a combination of T1-weighted, fat-saturated T2-weighted, and gradient-echo (flow-weighted) MR images. In this case axial plane was most helpful in depicting the relationship between the lesion, neurovascular structures, and tissue planes [14]

Management of hemangioma depends on a variety of factors, and most true hemangiomas require no intervention. There are many treatment modalities reported in the literature for head and neck hemangiomas, including wait and watch policy, for spontaneous involution, intralesional and systemic corticosteroid treatment, embolization, excision, electrolysis and thermocautery, immunomodulatory therapy with interferon alfa-2a, and laser photocoagulation [20,21] Currently, sclerotherapy is employed largely because of its efficiency and ability to conserve the surrounding tissues [22].

Sclerotherapy was chosen as a conservative treatment modality as it uses the physical, chemical, and biological properties of an agent to disrupt target tissue [23,24]. This disruption allows the formation of sclerosed or "hardened" by products that following therapy have drastically changed or diminished functions. It results not only in occlusion of vascular structures similar to embolization, but also may limit recurrence, proliferation, or collateralization by permanently disrupting the endothelium of targeted vascular structures.[25] Additionally, the biological effect extends beyond structures with an endothelium; the epithelial lining of true cysts, capillary beds, and lymphatic structures, as well as bone cysts, have been targeted successfully [23-25].

For an agent to have potential as a sclerosant, it must have a physical, chemical, and/or biologic effect on the target tissue and induce a controlled inflammatory response. The inflammatory response is a result of cell damage with fibroblast proliferation that leads to sclerosis. In addition to fibrosis, agents may produce other effects such as thrombosis, extraction of proteins from lipids, denaturation of proteins, cell dehydration by osmosis, and physical obstruction by polymerization. The result of these processes is controlled disruption of the targeted tissues biologic function [23]. For a sclerosant to be effective, it must diffuse to its target tissue through a fluid medium and interact with the target tissue for a sufficient period to begin the process leading to sclerosis. Among the sclerosing agents available, excellent results have been reported for sodium morrhuate, sodium sulfate tetradecyl, polidocanol and ethanolamine oleate, and hypertonic glucose solution [23].

Sodium tetradecyl sulfate is an anionic surfactant used as an intravascular sclerosing agent approved by the FDA. This has been widely employed in the management of vascular lesions [19,23]. This sclerosant has already been used in the treatment of varicoceles, vascular malformations of the extremities, upper gastrointestinal bleeding, variceal bleeding, hemorrhagic tumors, gallbladder ablation, lymphoceles, and percutaneous ablation of oral lesions of Kaposi sarcoma and ganglion cysts [19,23-25].

Literature reveals that 3\% STS is safe for treatment of such cases and usually the volume of $3 \%$ STS required is $1 / 4$ th the lesion size, i.e., $0.5 \mathrm{ml}$ of $3 \%$ STS for each $2 \mathrm{~cm}$ of lesion size [24]. Henceforth if the volume of the lesion is small, less amount of sclerosing agent will be injected. Furthermore Choi et al. [25] in 2016 highlightedthe manufacturer's instructions of $3 \%$ STS. It was revealed that at an instance $0.5-2.0 \mathrm{~mL}$ of $3 \%$ STS can be safely injected into a lesion per one dose [25]. In this present reported case, the same protocol was followed. But since the size of the lesion in our case was huge and we had to inject almost three times more volume, we used three times lesser concentration, i.e., $1 \%$ concentration to be on safer side. Further the frequency of injection depends upon the texture and size of the lesion on follow up. Since the lesion in our case was huge, repeated injections were performed. Once the desired effect was achieved, the injections were discontinued. Complications directly related to STS tend to be at the site of administration; extravasation at or near the site of injection during percutaneous treatments.

\section{LEARNING POINTS}

- Haemangioma is the most common benign tumour of vascular origin of the maxillofacial region and requires appropriate management as it may lead to an early or continuous loss of function or lifetime esthetic impairment.

- Usually such patients require surgical removal of the lesion. But in consideration to the massive surgical procedure, the treatment with $3 \%$ sodium tetradecyl sulphate can lead to successful remission of the lesion. This therapeutic approach may reduce the chances of the surgical requirement.

Author contributions: All authors have sufficiently contributed to the study, and agreed with the results and conclusions.

Funding: No funding source is reported for this study.

Declaration of interest: No conflict of interest is declared by authors.

\section{REFERENCES}

1. Çalifianeller T, Ozdemr O, Yildirim E. Cavernous Hemangioma of temporalis muscle: Report of a case and review of the literature. Turkish Neurosurgery 2007; 17(1): 33-6.

2. Karasu HA, Oncul AM, Uyanik LO. Cryosurgery of a huge hemangioma of tongue: A case report. J Oral Health Comm Dent 2010; 4 (3): 83-7. https://doi.org/10.5005/johcd-4-3-83

3. Alami B, Lamrani Y. Presumptive intramuscular hemangioma of the masseter muscle. Am J Case Rep, 2015; 16: 16-9. https://doi.org/10.12659/AJCR.890776 PMid: 25590509 PMCid:PMC4298281

4. Nair AB, Manjula BV, Balasubramanyam AM. Intramuscular haemangioma of mylohyoid muscle: A case report. Indian J Surg 2010; 72(Suppl 1): 344-46. https://doi.org/10.1007/ s12262-010-0079-3 PMid:23133293 PMCid:PMC3451854

5. He H, Du Z, Hao S, Yao L, Yang F, Di Y, et al. Adult primary retroperitoneal cavernous hemangioma: a case report. World Journal of Surgical Oncology 2012; 10: 261 https://doi.org/10.1186/1477-7819-10-261 PMid:23216883 PMCid:PMC3539936

6. Hashemipour MA. Rare cavernous haemangioma of the oral cavity with numerous phleboliths. J Oral Health Oral Epidemiol 2012; 1(1): 46-51.

7. Gill JS, Gill S, Bhardwaj A, Grover HS. Oral haemangioma. Case Report Med 2012. https://doi.org/10.1155/2012/ 347939 PMid:22431929 PMCid:PMC3295535

8. Dilsiz A, Aydin T, Gursan N. Capillary hemangioma as a rare benign tumor of the oral cavity: a case report. Cases Journal 2009; 2: 8622 https://doi.org/10.4076/1757-1626-28622 PMid:20181211 PMCid:PMC2827094 
9. Enzinger FM, Weiss SW. Soft tissue tumors. 3rd Edition. St Louis: Mosby; 1995:581-586.

10. Thomasa R, Ramalingama SBJ, Samuela J, Kumar KD. Cavernous hemangioma of The Uvula - A Case Report. Sri Ramachandra Journal of Medicine, 2009; 1(1): 36-7.

11. Jin SG, Kim MJ, Park JM, Park KH. A case of subcutaneous hemangioma presenting as a preauricular sinus. Korean $\mathrm{J}$ Audiol 2013; 17: 32-34. https://doi.org/10.7874/ kja.2013.17.1.32 PMid:24653902 PMCid:PMC3936520

12. Beham A, Fletcher CD. Intramuscular angioma: a clinicopathological analysis of 74 cases. Histopathology 1991; 18: 53-9. https://doi.org/10.1111/j.1365-2559.1991. tb00814.x PMid:2013460

13. Kishore S. A rare case of cavernous hemangioma in the tonsil. RJPBCS 2014; 5(2): 1962-5.

14. Donnelly LF, Adams DM, Bisset GS. Vascular malformations and hemangiomas: a practical approach in a multidisciplinary clinic. AJR Am J Roentgenol. 2000; 174(3): 597-608. https://doi.org/10.2214/ajr.174.3.1740597 PMid: 10701595

15. Saedi B, Hajipour A, Javid MJ. A Giant Hemangioma of the tongue. Iranian Journal of Otorhinolaryngology 2011; 23(1): 55-8. https://doi.org/10.22038/ijorl.2011.632

16. Chang JFM, ChenY. Intralesional photocoagulation of vascular anomalies of the tongue. Br J Plas Surg 1999; 52: 178-81. https://doi.org/10.1054/bjps.1998.3056 PMid: 10474467

17. Apfelberg DP. Treatment of hemangiomas. In: Georgiade GS: Textbook of plastic, maxillofacial and reconstructive surgery. Williams \& Wilkins, 1992: 223-29.

18. Nosher JL, Murillo PG, Liszewski M, Gendel V, Gribbin CE. Vascular anomalies: A pictorial review of nomenclature, diagnosis and treatment. World J Radiol 2014 September 28; 6(9): 677-692. https://doi.org/10.4329/wjr.v6.i9.677 PMid:25276311 PMCid:PMC4176785
19. Ernemann U, Kramer U, Miller S, Bisdas S, Rebmann H, Breuninger $\mathrm{H}$, et al. Current concepts in classification, diagnosis and treatment of vascular anomalies. European journal of radiology 2010; 75: 2-11. https://doi.org/10.1016/ j.ejrad.2010.04.009 PMid:20466500

20. Kamala KA, Ashok L, Sujatha GP. Cavernous hemangioma of the tongue: A rare case report. Contemporary Clinical Dentistry, January-March, 2014; 5(1): 95-98. https://doi.org/10.4103/0976-237X.128680 PMid:24808705 PMCid:PMC4012128

21. Atkins JH, Mandel JE, Mirza N. Laser ablation of a large tongue hemangioma with remifentanil analgosedation in the ORL endoscopy suite. ORL J Otorhinolaryngol Relat Spec 2011; 73: 166-9. https://doi.org/10.1159/000328341 PMid:21613798

22. Bonet- Coloma C, Mínguez-Martínez I, Palma-Carrió C, Galan-Gil S, Penarroche-Diago M, Minguez-Sanz JM. Clinical characteristics, treatment and outcome of 28 oral hemangiomas in pediatric patients. Med Oral Patol Oral Cir Bucal. 2011; 16: e19-22. https://doi.org/10.4317/medoral. 16.e19 PMid:20711165

23. Okoji VN, Alonge TO, Olusanya AA. Intra-tumoral ligation and the injection of sclerosant in the treatment of lingual cavernous hemangioma. Niger J Med. 2011; 20: 172-5.

24. Alakailly X, Kummoona R, Quereshy FA, Baur DA, Gonza'lez $A E$. The Use of Sodium Tetradecyl Sulphate for the Treatment of Venous Malformations of the Head and Neck. J. Maxillofac. Oral Surg. 2015;14(2):332-8. https://doi.org/ 10.1007/s12663-014-0623-y PMid:26028855 PMCid: PMC4444672

25. Choi B, Kim Y, Leem D, Baek J, Ko S. Utility of sodium tetradecyl sulphate sclerotherapy from benign oral vascular lesion. Maxillofacial Plastic and Reconstructive Surgery 2016; 38:44. https://doi.org/10.1186/s40902-0160094-9 PMid:27995117 PMCid:PMC5122605 